\title{
Impedance method with interpolation applied to skin impedance modeling
}

\author{
Airton Ramos*
}

Abstract A new approach based on the use of interpolation for the electric potential is proposed to increase the accuracy of field calculation using the impedance method. In each voxel of a three-dimensional grid, the electric field is calculated from the potential interpolation function and is used as a solution of the continuity equation. The system of node equations is then solved and the resulting potential distribution obtained allows making the calculation of the electric field and current in each voxel. In this work, the proposed method was used to estimate the sensitivity of a tetrapolar probe in detecting small regions of increased conductivity in a stratified model of human skin. The simulations indicated that inserting a tumor in the epidermis with area $1 \mathrm{~mm}^{2}$ and admittivity fourfold than the normal tissue the load impedance to the current source varies from about $1 \%$ while the transfer impedance shows much greater variation, about $8 \%$. Additionally, it was found that the sensitivity of the transfer impedance shows a maximum for electrodes of $1 \mathrm{~mm}$ in diameter with spacing of $1.8 \mathrm{~mm}$ and for both impedances the sensitivity is independent of the frequency.

Keywords Impedance method, Field calculation, Skin impedance, Skin tumor, Tetrapolar probe, Sensitivity.

\section{Método da impedância com interpolação aplicado à modelagem da impedância da pele}

Resumo Uma nova abordagem baseada no uso de interpolação para o potencial elétrico é proposto com o objetivo de aumentar a precisão do cálculo de campo usando o método da impedância. Em cada voxel de um grid tridimensional, o campo elétrico é calculado a partir da função de interpolação de potencial e é usado como uma solução da equação de continuidade. O sistema de equações de nós é então resolvido e a distribuição de potencial resultante obtida permite o cálculo do campo elétrico e da corrente em cada voxel. Neste trabalho, o método proposto foi utilizado para estimar a sensibilidade de uma sonda tetrapolar na detecção de pequenas regiões de condutividade aumentada em um modelo estratificado da pele humana. As simulações indicam que a inserção de um tumor na epiderme com área igual a $1 \mathrm{~mm}^{2}$ e admitância quatro vezes maior que a do tecido normal resulta em uma variação da impedância de carga para a fonte de corrente em cerca de 1\%, enquanto a impedância de transferência mostra uma variação muito maior, em torno de 8\%. Além disso, verificou-se que a sensibilidade da impedância de transferência atinge seu máximo para eletrodos de $1 \mathrm{~mm}$ de diametro, com espaçamento de 1,8 mm e, para ambas as impedâncias, a sensibilidade é independente da frequência.

Palavras-chave Método da impedância, Cálculo de campo, Impedância da pele, Tumor de pele, Sonda tetrapolar, Sensibilidade. 


\section{Introduction}

The impedance method and similar methods use lumped parameters of electric circuit to model the electric properties of the related materials (Orcutt and Gandhi, 1988; Ramos et al., 2003). Such methods have been applied in various important situations in electromagnetic modeling especially involving linear media with sinusoidal excitation where the technique of fasorial analysis can be applied (Nadeem et al., 2003; Ramos, 2005). Both are based on quasi static approximation of the equations of electromagnetic theory that provides accurate results when the dimensions of the media are small compared with the wavelength corresponding to the frequency of the excitation source and when the selfinductance effects can be neglected. The properties conductivity and permittivity are modeled by means of electrical circuit elements such as conductance and capacitance that connect neighboring voxels in the three-dimensional discretization grid. Figure 1 illustrates the connection between two adjacent voxels of the grid. The admittance of connection is calculated by the following expression:

$Y=(\sigma+i \omega \varepsilon) \frac{A}{L}$

where $\sigma$ is the conductivity and $\varepsilon$ is the permittivity of the media. $A$ is the area of contact and $L$ is the distance between the centers of the two neighbors voxels. $\omega$ is the angular frequency of the applied field and $i=\sqrt{-1}$. This equation was obtained assuming that the electric field is uniform in the space between the two voxels. For this approach does not produce big errors in calculating the electric potential, one has to use highly resolved discretization meshes. This implies a large number of nodes and therefore in great demand of memory and processing time. An important

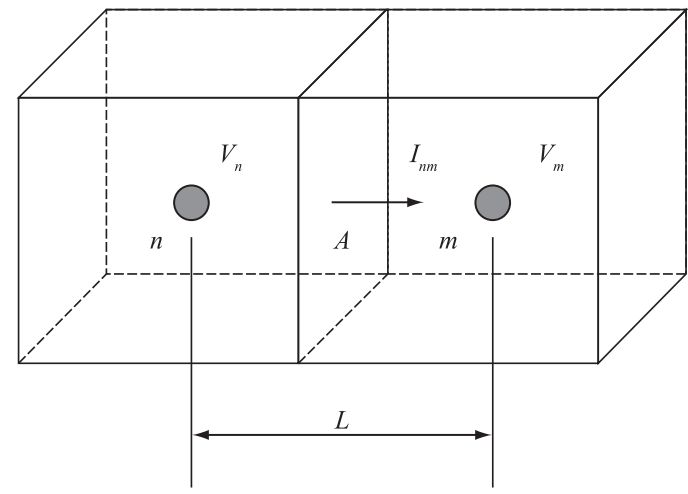

Figure 1. Connection between two voxels in the discretization mesh in the Impedance Method. limitation of the impedance method lies in the fact that it allows the calculation of potential or current only in discrete positions of the mesh, which tends to intensify the discretization error. This problem can be minimized with the use of interpolation to represent the distribution of potential within each voxel as it is done in the finite element method.

This article has as its main objective to present a new strategy for numerical modeling with the impedance method that uses interpolation to describe the potential and electric field within the voxels of the discretization mesh. We also present an important application of the proposed method in the modeling of the electrical impedance of the skin when measured by a tetrapolar system of surface electrodes. This experimental technique presents an important potential of application in noninvasive and early detection of skin lesions, such as tumors, which show significant differences in the electrical properties of the damaged tissue when compared to normal tissue.

\section{Methods}

Figure 2 shows a voxel with a local numbering of nodes in its corners. This numbering is identical for all voxels of the mesh. Furthermore, each node is identified by a set of three indexes allocated in accordance with its position in relation to the origin of the reference system. The electric potential inside the voxel is described by the following function:

$$
\begin{aligned}
V & =k_{0}+k_{1} x^{\prime}+k_{2} y^{\prime}+k_{3} z^{\prime}+k_{4} x^{\prime} y^{\prime} \\
& +k_{5} x^{\prime} z^{\prime}+k_{6} y^{\prime} z^{\prime}+k_{7} x^{\prime} y^{\prime} z^{\prime}
\end{aligned}
$$

in the intervals $0 \leq x^{\prime} \leq \Delta x, 0 \leq y^{\prime} \leq \Delta y, 0 \leq z^{\prime} \leq \Delta z$. The coefficients $(k)$ of the interpolation function are

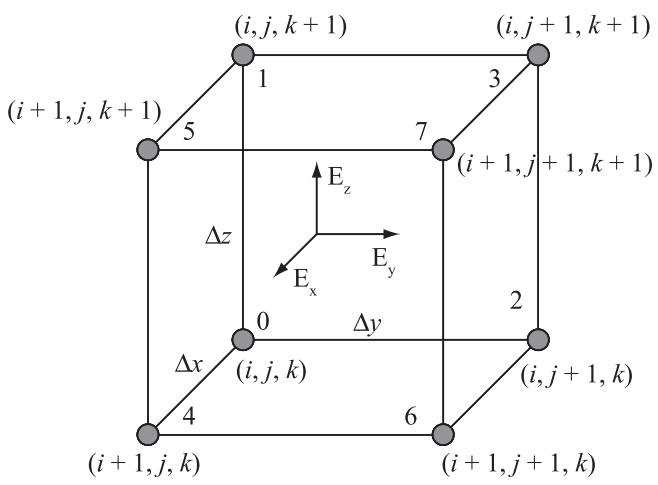

Figure 2. Representation of a voxel with the numbering of its nodes and internal electric field. 
dependent on the node potentials and are given by the following equations:

$$
\begin{aligned}
& k_{0}=V_{0} \\
& k_{1}=\left(V_{4}-V_{0}\right) / \Delta x \\
& k_{2}=\left(V_{2}-V_{0}\right) / \Delta y \\
& k_{3}=\left(V_{1}-V_{0}\right) / \Delta z \\
& k_{4}=\left(V_{6}+V_{0}-V_{4}-V_{2}\right) / \Delta x \Delta y \\
& k_{5}=\left(V_{5}+V_{0}-V_{4}-V_{1}\right) / \Delta x \Delta z \\
& k_{6}=\left(V_{3}+V_{0}-V_{2}-V_{1}\right) / \Delta y \Delta z \\
& k_{7}=\left(V_{7}+V_{4}+V_{2}+V_{1}-V_{6}-V_{5}-V_{3}-V_{0}\right) / \Delta x \Delta y \Delta z
\end{aligned}
$$

From Equation 2 we obtain the electric field and calculate the current density in each direction of the reference system in each voxel:

$$
\begin{aligned}
& j_{x}=\gamma_{x} E_{x}=-\left(\sigma_{x}+j \omega \varepsilon_{x}\right)\left(k_{1}+k_{4} y^{\prime}+k_{5} z^{\prime}+k_{7} y^{\prime} z^{\prime}\right) \\
& j_{y}=\gamma_{y} E_{y}=-\left(\sigma_{y}+j \omega \varepsilon_{y}\right)\left(k_{2}+k_{4} x^{\prime}+k_{6} z^{\prime}+k_{7} x^{\prime} z^{\prime}\right) \\
& j_{z}=\gamma_{z} E_{z}=-\left(\sigma_{z}+j \omega \varepsilon_{z}\right)\left(k_{3}+k_{5} x^{\prime}+k_{6} y^{\prime}+k_{7} x^{\prime} y^{\prime}\right)
\end{aligned}
$$

where $\gamma=\sigma+j \omega \varepsilon$ is the admittivity of the media inside the voxel. By integrating the current density under the assumption that conductivity and permittivity are uniform inside the voxel, we get the current coming out of the voxel in each direction of the reference system in the form of Equations 7, 8 and 9 in which the current is described by a function of the expansion coefficients of the potential on node $(i, j, k)$ and adjacent nodes.

$$
I_{x}(i, j, k)=-\frac{\Delta y \Delta z}{64}\left\{\begin{array}{l}
{\left[\gamma_{x}\left(16 k_{1}+12 k_{4} \Delta y+12 k_{5} \Delta z+9 k_{7} \Delta y \Delta z\right)\right]_{(i, j-1, k-1)}} \\
+\left[\gamma_{x}\left(16 k_{1}+4 k_{4} \Delta y+12 k_{5} \Delta z+3 k_{7} \Delta y \Delta z\right)\right]_{(i, j, k-1)} \\
+\left[\gamma_{x}\left(16 k_{1}+12 k_{4} \Delta y+4 k_{5} \Delta z+3 k_{7} \Delta y \Delta z\right)\right]_{(i, j-1, k)} \\
+\left[\gamma_{x}\left(16 k_{1}+4 k_{4} \Delta y+4 k_{5} \Delta z+k_{7} \Delta y \Delta z\right)\right]_{(i, j, k)}
\end{array}\right\}(7)
$$$$
I_{y}(i, j, k)=-\frac{\Delta x \Delta z}{64}\left\{\begin{array}{l}
{\left[\gamma_{y}\left(16 k_{2}+12 k_{4} \Delta x+12 k_{6} \Delta z+9 k_{7} \Delta x \Delta z\right)\right]_{(i-1, j, k-1)}} \\
+\left[\gamma_{y}\left(16 k_{2}+4 k_{4} \Delta x+12 k_{6} \Delta z+3 k_{7} \Delta x \Delta z\right)\right]_{(i, j, k-1)} \\
+\left[\gamma_{y}\left(16 k_{2}+12 k_{4} \Delta x+4 k_{6} \Delta z+3 k_{7} \Delta x \Delta z\right)\right]_{(i-1, j, k)} \\
+\left[\gamma_{y}\left(16 k_{2}+4 k_{4} \Delta x+4 k_{6} \Delta z+k_{7} \Delta x \Delta z\right)\right]_{(i, j, k)}
\end{array}\right\}
$$

$$
I_{z}(i, j, k)=-\frac{\Delta x \Delta y}{64}\left\{\begin{array}{l}
{\left[\gamma_{z}\left(16 k_{3}+12 k_{5} \Delta x+12 k_{6} \Delta y+9 k_{7} \Delta x \Delta y\right)\right]_{(i-1, j-1, k)}} \\
+\left[\gamma_{z}\left(16 k_{3}+4 k_{5} \Delta x+12 k_{6} \Delta y+3 k_{7} \Delta x \Delta y\right)\right]_{(i, j-1, k)} \\
+\left[\gamma_{z}\left(16 k_{3}+12 k_{5} \Delta x+4 k_{6} \Delta y+3 k_{7} \Delta x \Delta y\right)\right]_{(i-1, j, k)} \\
+\left[\gamma_{z}\left(16 k_{3}+4 k_{5} \Delta x+4 k_{6} \Delta y+k_{7} \Delta x \Delta y\right)\right]_{(i, j, k)}
\end{array}\right\}
$$

In order to obtain a relationship between the potential of nodes that meets the principle of continuity we establish that the sum of all components of current entering (negative) or leaving (positive) any node of the grid is zero. The resulting equation contains all the potential of nodes of the eight voxels that contains the common node $(i, j, k)$. That is, this equation relates potential of 27 nodes. It can be written in the following general form:

$$
\sum_{n=-1}^{1} \sum_{m=-1}^{1} \sum_{r=-1}^{1} a(n, m, r) V(i+n, j+m, k+r)=I_{s}(i, j, k)
$$

where $n, m$ and $r$ are integers that can take the values 1,0 or -1 and $I_{s}$ is the current injected in the node $(i, j, k)$ by the external source. The coefficients $(n, m, r)$ relates the admittance of the eight voxels involved in each node equation.

The numerical simulation method consists of solving the equations described by (10) (one equation for each node in the mesh) in order to obtain the node potential distribution in the boundary conditions defined previously. The sources are represented either as applying potential or injecting current through electrodes, which are connected to some nodes of the system. On the boundary surfaces it is applied the homogeneous Neumann condition. The source current is only defined when the electrode is in contact with a single voxel. For electrodes with larger area than the voxel face the source have to be described by an applied potential. In this case, the injecting current in the mesh is calculated by the total amount of power dissipated in the volume, which results in the following equation:

$$
I_{s}=\frac{1}{V_{s}} \sum_{n}\left[\int_{0}^{\Delta x} \int_{0}^{\Delta y} \int_{0}^{\Delta z}\left(\gamma_{x} E_{x}^{2}+\gamma_{y} E_{y}^{2}+\gamma_{z} E_{z}^{2}\right) d x d y d z\right]_{n}
$$

where the sum extends over all voxels. The calculated potential from the measuring electrodes is done by defining supernodes that put together all nodes which are in contact with these electrodes. All these nodes are in the same electrical potential as the contact surface electrode.

\section{Numerical model of human skin and measurement system}

Electrical impedance measurement can be used as a noninvasive and objective method for detecting skin tumors (Aberg et al., 2004; 2005; Beetner et al., 2003; Glickman et al., 2003). Based on in vitro measurements in tumors, it was found that these tissues show an increasing conductivity and permittivity in a wide frequency range covering tens of megahertz (Jones et al., 2003; Surowiec et al., 1988). This is mainly due to changes in shape and size of cells, cell nucleus and the spacing between cells within the tumor. The sensitivity in detecting a region with different admittivity within the normal tissue by electrical impedance measurements made on the skin surface is defined by the following equation:

$$
S=\Delta Z / Z
$$


where $Z$ is the measured impedance of the normal tissue and $\Delta Z$ is the impedance variation of the pathological tissue. The model of skin and measurement system is shown in Figure 3. It consists of a regular volume excited by a pair of electrodes that inject a known current in the skin. A second pair of electrodes measures the difference in electric potential between two points on this surface. The load impedance and transfer impedance are defined respectively by the following equations:

$$
\begin{aligned}
& Z_{o}=V_{s} / I_{s} \\
& Z_{t}=V_{m} / I_{s}
\end{aligned}
$$

The skin model used has three layers, epidermis, dermis and hypodermis, with thickness $1 \mathrm{~mm}$, $2 \mathrm{~mm}$ and $1 \mathrm{~mm}$, respectively. The conductivity and permittivity for epidermis in the frequency range from $100 \mathrm{~Hz}$ to $1 \mathrm{MHz}$ were obtained from published results (Gabriel et al., 1996). For dermis and hypodermis, in the absence of published experimental values, it was assumed that the conductivity and permittivity are the half and one tenth of the epidermis value at the same frequency, respectively. Below the surface and centered with the tetrapolar scheme of electrodes, a tumor is modeled by a cylindrical volume with conductivity and permittivity four times the value for the normal tissue. The tumor model has an area of $1 \mathrm{~mm}^{2}$, thickness of $0.4 \mathrm{~mm}$ and a depth of $0.6 \mathrm{~mm}$. The regular grid was built with 140 divisions on the $x$-axis, 140 divisions on the $y$-axis and 40 divisions on the $z$-axis. Each voxel was a cube with $0.1 \mathrm{~mm}$ edge.

\section{Results and Analysis}

Figure 4 shows how both impedance $(Z)$ and sensitivity $(S)$ vary by changing the diameter and the electrode separation in the frequency of $1 \mathrm{MHz}$. The conductivity and dielectric constant of epidermis in this frequency are $0.5 \mathrm{~S} / \mathrm{m}$ and $3 \times 10^{3}$, respectively (Gabriel et al., 1996). There are significant differences in the behavior of two impedances. The load impedance $Z_{\mathrm{o}}$ (dashed lines) increases slightly by increasing the distance between electrodes but decreases sharply with increasing the electrodes diameter. However, the transfer impedance $Z_{t}$ (continuous lines) decreases with increasing the distance between electrodes and almost it does not depend on the electrodes diameter. Regarding the sensitivity, it can be observed that the load impedance varies approximately $1 \%$ by including the tumor and it is almost not dependent on the electrode diameter and on the distance between electrodes. This small sensitivity to load change turns the technique not accurate to identify tumor,

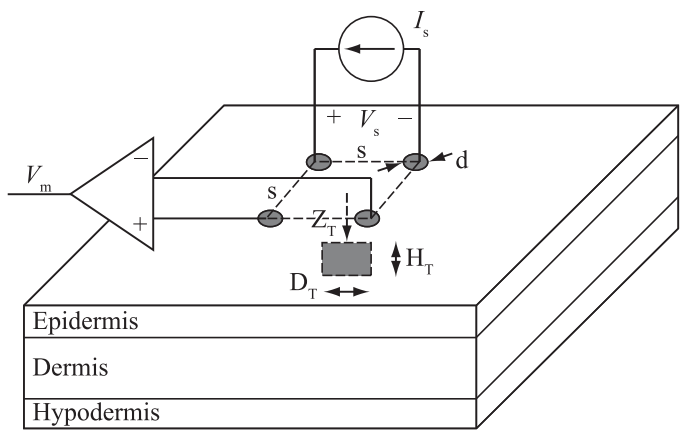

Figure 3. Model of skin, tumor and measurement system used in the simulation.
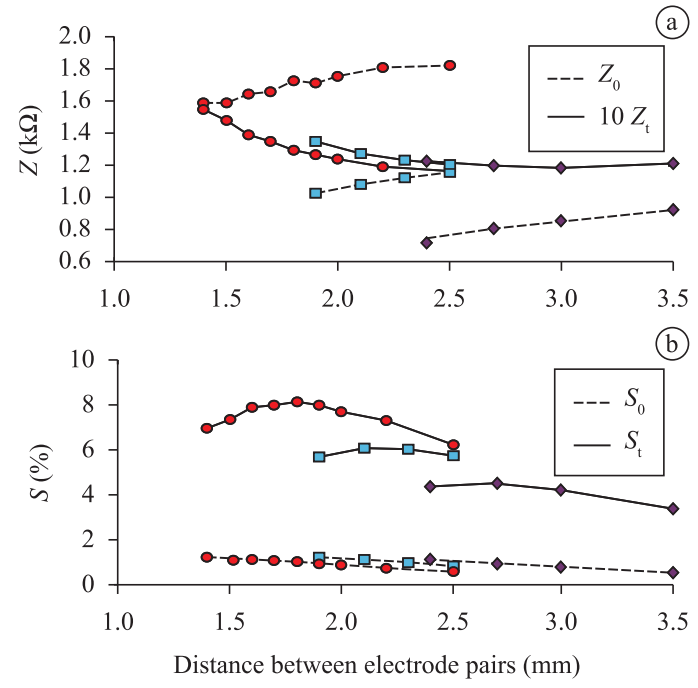

Figure 4. Impedance and sensitivity dependence upon electrode diameter and distance between electrodes for a tetrapolar probe. Tumor model with area of $1 \mathrm{~mm}^{2}$, thickness of $0.4 \mathrm{~mm}$ and depth of $0.6 \mathrm{~mm}$. a) Load impedance modulus and transfer impedance modulus magnified 10 times; b) Load impedance sensitivity. (0) $\mathrm{d}=1 \mathrm{~mm}$, $(\square) \mathrm{d}=1.5 \mathrm{~mm},(\diamond) \mathrm{d}=2 \mathrm{~mm}$.

especially if it is taken into account the electrode-skin interface impedance. This interface impedance is in series with the load impedance, hence the sensitivity value is even smaller and so it is difficult to be predicted. Furthermore, the interface impedance is an unpredictable figure in this technique as it depends on the skin preparation and on the electrode surface type. On the other hand, the transfer impedance sensitivity is higher and varies significantly with increasing the electrode diameter and the distance between electrodes. It can be observed that the maximum sensitivity occurred for an electrode diameter of $1 \mathrm{~mm}$ and separation of $1.8 \mathrm{~mm}$. This may be explained by the fact that the transfer impedance and its change $\Delta Z_{t}$ do not vary proportionally with increasing the distance 
between electrodes. For example, in the interval between $1.4 \mathrm{~mm}$ and $1.8 \mathrm{~mm} Z$ decreases faster than $\Delta Z$ and so the sensitivity increases but after $1.8 \mathrm{~mm}$ this tendency is inverted. The voltage difference in the receive electrodes can be measured by a high input impedance instrumentation amplifier so that the electrode-skin interface impedance do not influence significantly the result. Thus, it can be concluded that the tetrapolar probe transfer impedance data have significant advantages to detect tumor when compared to the load impedance data from bipolar technique.

In order to investigate the frequency response of the tetrapolar probe sensitivity, simulations were carried out for both $Z_{\mathrm{o}}$ and $Z_{t}$. Table 1 shows the results of the simulations by varying the source frequency from 0.1 to $1,000 \mathrm{kHz}$. It was observed that although the impedance decreases with increasing frequency, both sensitivity $S_{0}$ and $S_{t}$ do not change. However, it was not taken into account the dielectric dispersion spectrum difference between tumor and normal tissue, that is, the admittivity ratio between tumor and normal tissue was assumed to be constant for all frequencies. If the dielectric dispersion of tumor and normal tissue are different it is expected a variation in the sensitivity with frequency. Since different types of tumor have different impedance frequency spectrum (Aberg et al., 2004), this might be used to measure the sensitivity change in order to identify tumor types. It also can be noticed that the load impedance is about 13 times bigger than the transfer impedance and this ratio does not depend on frequency.

Table 1. Impedance and sensitivity for various frequencies with tetrapolar probe (diameter $1 \mathrm{~mm}$, spacing $1.8 \mathrm{~mm}$ ). Conductivity and dielectric constant data obtained from (Gabriel et al., 1996).

\begin{tabular}{ccccccc}
\hline $\begin{array}{c}\mathbf{f} \\
(\mathbf{k H z})\end{array}$ & $\begin{array}{c}\sigma \\
(\mathbf{S} / \mathbf{m})\end{array}$ & $\begin{array}{c}\varepsilon_{\mathrm{r}} \\
\left(\mathbf{1 0}^{3}\right)\end{array}$ & $\begin{array}{c}\left|\boldsymbol{Z}_{\mathbf{0}}\right| \\
(\mathbf{k} \boldsymbol{\Omega})\end{array}$ & $\begin{array}{c}\left|\boldsymbol{Z}_{\mathrm{t}}\right| \\
(\boldsymbol{\Omega})\end{array}$ & $\begin{array}{c}\boldsymbol{S}_{\mathbf{0}} \\
(\mathbf{\%})\end{array}$ & $\begin{array}{c}\boldsymbol{S}_{\boldsymbol{t}} \\
(\mathbf{\%})\end{array}$ \\
\hline 0.1 & 0.20 & 400 & 4.54 & 340.73 & & \\
1 & 0.25 & 200 & 3.63 & 272.33 & & \\
10 & 0.30 & 100 & 2.98 & 223.36 & 1.02 & 8.14 \\
100 & 0.35 & 30 & 2.34 & 175.77 & & \\
1000 & 0.50 & 3 & 1.72 & 129.30 & & \\
\hline
\end{tabular}

\section{Conclusion}

A new approach to the impedance method was presented. This technique uses interpolation to calculate the electric potential in the voxels and the continuity equation or Kirchhoff's first law for calculating the potential of nodes in an equivalent circuit of the media. The proposed method is easy to implement and appropriate to calculate the distribution of potential, field and electric current in biological tissues whose electrical properties are known. According to the results obtained in this work, the technique of measuring the transfer impedance with a tetrapolar probe provides a good sensitivity when detecting small tumors in the skin. For the tumor model used in the simulations it was found that the load impedance sensitivity is approximately $1 \%$ whereas the transfer impedance sensitivity has a maximum of $8 \%$. In addition, it was found that the sensitivity does not depend on frequency if tumor and normal tissue have the same dielectric dispersion. If any dependence is observed this can be used to identify the type of tumor. It can be concluded that the tetrapolar impedance probe method can be used for detecting small tumors. The findings encountered in this work might be used to diagnose the skin cancer in the early stages.

\section{References}

Aberg P, Geladi P, Nicander I, Hansson J, Holmgren U, Ollmar S. Non-invasive and micro invasive electrical impedance of skin cancer - a comparison between two techniques. Skin Research and Technology. 2005; 11:281286. PMid:16221145. http://dx.doi.org/10.1111/j.0909725X.2005.00125.x

Aberg P, Nicander I, Hansson J, Geladi P, Holmgren U. Skin cancer identification using multifrequency electrical impedance - a potential screening tool. IEEE Transaction on Biomedical Engineering. 2004; 51:20972102. PMid:15605856. http://dx.doi.org/10.1109/ TBME.2004.836523

Beetner DG, Kapoor S, Manjunath S, Zhou X, Stoecker WV. Differentiation among cell carcinoma, benign lesions and normal skin using electrical impedance. IEEE Transaction on Biomedical Engineering. 2003; 50:1020-1025. PMid:12892329. http://dx.doi.org/10.1109/ TBME.2003.814534

Gabriel C, Gabriel S, Corthout E. The dielectric properties of biological tissues: I. Literature survey. Physics in Medicine and Biology. 1996; 41:2231-2249. PMid:8938024. http://dx.doi.org/10.1088/0031-9155/41/11/001

Glickman YA, Filo O, David M, Yayon A, Topaz M, Zamir B, Ginzburg A, Rozenman D, Kenan G. Electrical impedance scanning: a new approach to skin cancer diagnosis. Skin Research and Technology. 2003; 9:262-268. PMid:12877689. http://dx.doi.org/10.1034/j.1600-0846.2003.00022.x

Jones DM, Smallwood RH, Hose DR, Brown BH, Walker DC. Modeling epithelial tissue impedance using three different designs of probe. Physiological Measurement. 2003; 24:605-623. PMid:12812442. http://dx.doi.org/10.1088/0967$3334 / 24 / 2 / 369$

Nadeem M, Thorleif T, Gandhi OP. Computation of electric and magnetic stimulation in human head using the 3-D impedance method. IEEE Transaction on Biomedical Engineering. 2003; 50:900-907. PMid:12848358. http://dx.doi.org/10.1109/TBME.2003.813548 
Orcutt N, Gandhi OP. A 3-D impedance method to calculate power deposition in biological bodies subjected to time varying magnetic fields. IEEE Transaction on Biomedical Engineering. 1988; 35:577-583. PMid:3049307. http://dx.doi.org/10.1109/10.4590

Ramos A. Effect of the electroporation in the field calculation in biological tissues. Artificial Organs. 2005; 29:510-513. PMid:15926990. http://dx.doi.org/10.1111/j.15251594.2005.29085.x
Ramos A, Raizer A, Marques JLB. A new computational approach for electrical analysis of biological tissues. Bioelectrochemistry. 2003; 59:73-84. http://dx.doi. org/10.1016/S1567-5394(03)00004-5

Surowiec AJ, Stuchly SS, Barr JR, Swarup A. Dielectric Properties of breast carcinoma and the surround tissues. IEEE Transaction on Biomedical Engineering. 1988; 35:257-263. PMid:2834285. http://dx.doi.org/10.1109/10.1374

\section{Author}

\section{Airton Ramos}

Department of Electrical Engineering, Centre of Technological Science, University of Santa Catarina State - UDESC CEP 89223-100, Joinville, SC, Brazil 